\title{
Successful Closure of Bronchopleural Fistula by Catheter-Assisted Intrabronchiolar Insertion of Microvascular Plug: A Case Report
}

\author{
Rashid Nadeem ${ }^{a} \quad$ Ashraf M. Elhoufi ${ }^{a}$ Raed H. Abuhijleh ${ }^{a}$ Ayman Saleh $^{b}$ \\ Ahmed N. Zahra ${ }^{a}$ \\ ${ }^{a}$ Department of Intensive Care, Dubai Hospital, Dubai Health Authority, Dubai, United Arab Emirates; \\ ${ }^{b}$ Department of Radiology, Dubai Hospital, Dubai Health Authority, Dubai, United Arab Emirates
}

\section{Keywords}

Bronchopleural fistula · Microvascular plug $\cdot$ Pneumothorax candidates for surgical or endoscopic repair, radiologically guided application of an occluding device or sealants are attractive options.

(C) 2019 The Author(s)

Published by S. Karger AG, Basel

\begin{abstract}
Bronchopleural fistula (BPF) is a pathological connection between the bronchial tree and pleural space usually formed as a result of local or systemic illness affecting pulmonary or pleural tissue. It is associated with significant morbidity and prolonged stay in the hospital. We present the case of a 33-year-old male with multiple sclerosis with multiple co-morbidities who developed respiratory failure from pneumonia requiring mechanical ventilation (MV) and tracheostomy. He developed pneumothorax which remained persistent despite medical management and chest tube insertion suggesting BPF. A high-resolution CT chest confirmed BPF. The patient was not a suitable candidate for endoscopic or surgical repair. An occlusive microvascular plug was placed under fluoroscopy to close the leak. Highresolution chest CT confirmed resolution of air leak. The patient was subsequently discharged to a long-term ventilator facility for liberation of MV. Follow-up after discharge revealed successful liberation from the ventilator. BPF management is a challenge which requires multidisciplinary approach and careful assessment to choose the best approach for treatment especially in high-risk patients with a compromised pulmonary status. For patients who are not suitable
\end{abstract}

\section{Introduction}

Bronchopleural fistula (BPF) is a pathological connection between the bronchial tree and pleural space usually formed as a result of local or systemic illness effecting pulmonary or pleural tissue. It is associated with significant morbidity and prolonged stay in the hospital [1]. Management of BPF is individualized, depending upon the pathology, location of fistula, goal of treatment, and available technology/expertise [2]. Effective management of $\mathrm{BPF}$ is a challenge [3]. In the majority of postoperative fistulas, surgical repair is performed via thoracotomy [4]. Interventional bronchoscopy is also very effective as nonoperative alternative for treatment of smaller air leaks, i.e. alveolo-pleural fistula [5]. Management of BPF is even more difficult in patients who are poor surgical candidates and who have poor pulmonary status precluding safe endoscopic intervention. We present a case of BPF which was treated by radiologically guided, catheter-assisted insertion of a microvascular plug.

\begin{tabular}{ll}
\hline KARGER & $\begin{array}{l}\text { ( } 2019 \text { The Author(s) } \\
\text { Published by S. Karger AG, Basel }\end{array}$ \\
E-Mail karger@karger.com & $\begin{array}{l}\text { This article is licensed under the Creative Commons Attribution- } \\
\text { NonCommercial-NoDerivatives 4.0 International License (CC BY- } \\
\text { NC-ND) (http://www.karger.com/Services/OpenAccessLicense). } \\
\text { Usage and distribution for commercial purposes as well as any dis- } \\
\text { tribution of modified material requires written permission. }\end{array}$
\end{tabular}

Rashid Nadeem, MD, FACP, FCCP, FAASM

Department of Intensive Care Medicine

Dubai Hospital, Dubai Health Authority, PO Box 7272

Dubai (United Arab Emirates)

E-Mail rnadeem@dha.gov.ae 

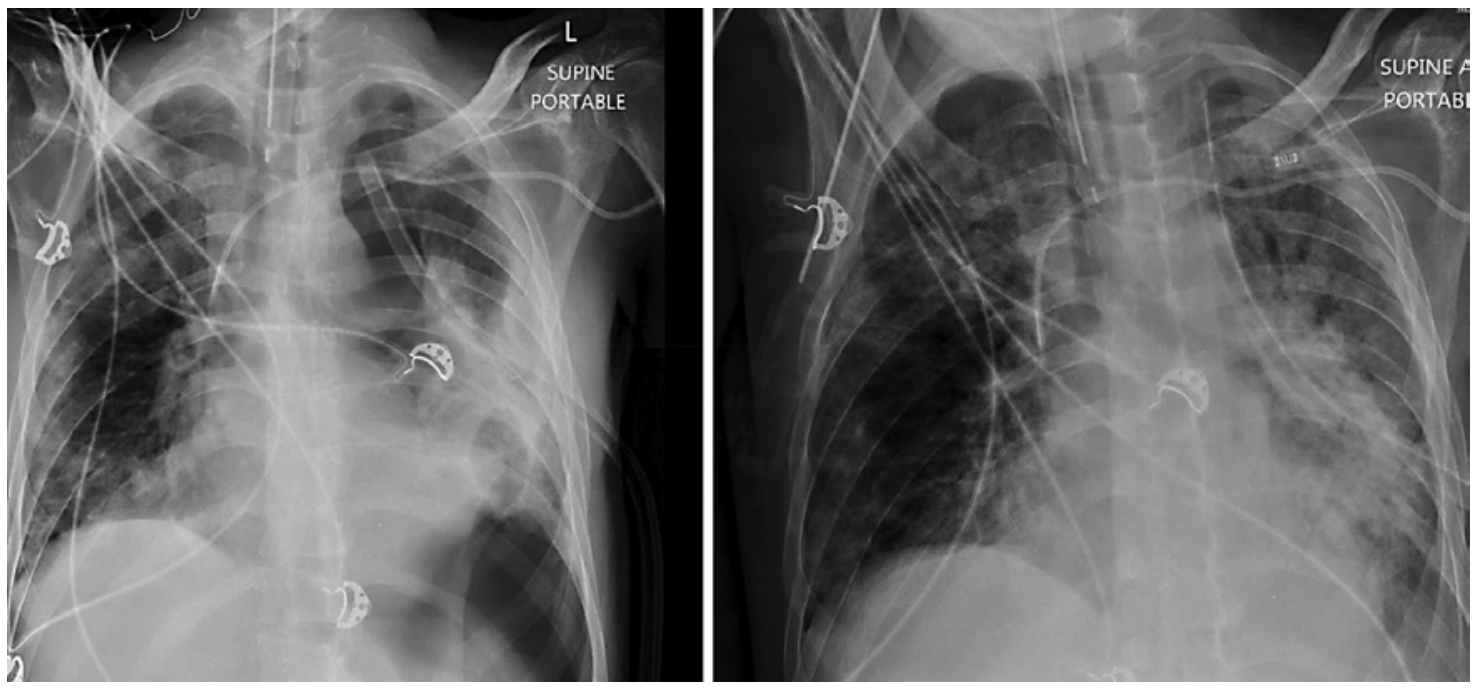

Fig. 1. Pneumothorax and its persistence after chest tube placement.
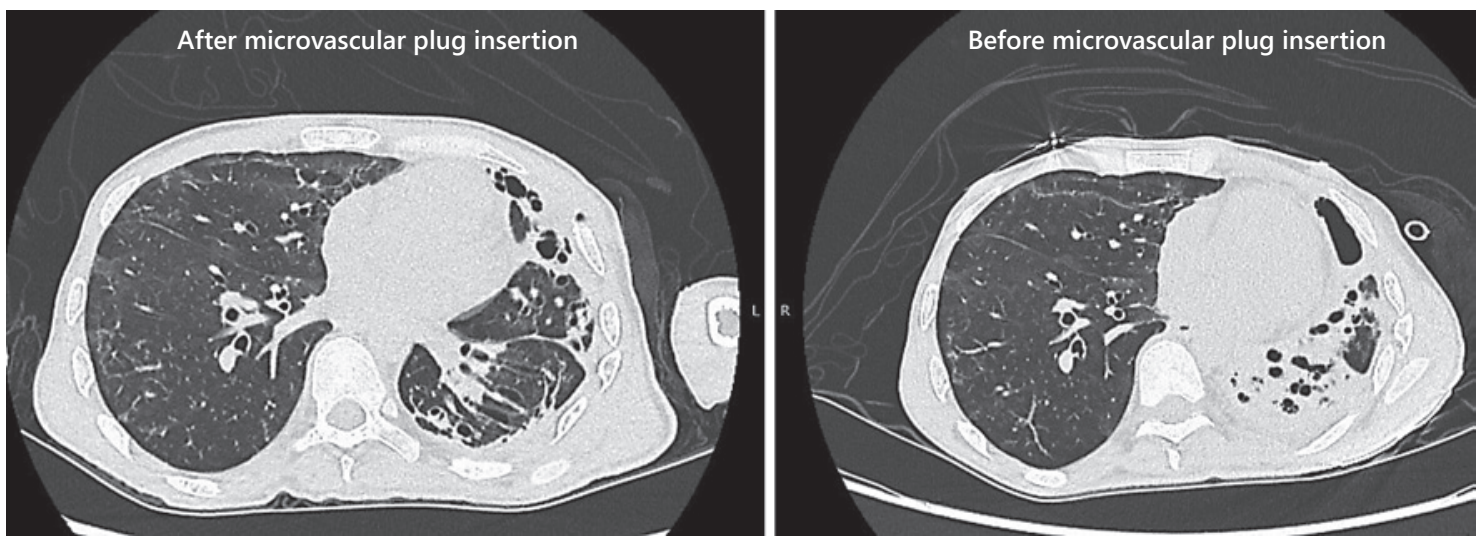

Fig. 2. HRCT of the chest before and after endobronchial device placement.

\section{Case Report}

The patient was a 33-year-old male with multiple sclerosis, urolithiasis, multiple urinary tract infections, and pneumonia. He had been bedbound for more than a year. He presented to us with respiratory failure from pneumonia and required prolonged mechanical ventilation (MV) and tracheostomy. The patient was ventilated with low tidal volume ( $6 \mathrm{~mL} / \mathrm{kg}$ ideal body weight) $\mathrm{MV}$, and plateau pressure was maintained below 30 . He developed pneumothorax which remained unresolved (Fig. 1) after chest tube insertion suggesting BPF. A high-resolution CT chest confirmed the presence of a $10 \times$ $10 \mathrm{~cm}$ pocket of pneumothorax in the left upper pleural cavity with a compressed and poorly ventilated left lower lobe of the lung. BPF failed to heal with medical management with oxygen therapy, chest tube evacuation, and appropriate antimicrobial treatment for pneumonia. Cardiothoracic surgery evaluated and determined that the patient was at high operative risk with unsuitable anatomy for surgical repair. Moreover, the Interventional Bronchology service determined that the patient could not be safely treated with endoscopi- cally placed occluding devices because of poor pulmonary status. Therefore, a multidisciplinary discussion determined that such a device may be safely inserted by the Interventional Radiology (IR) service since a catheter occupies less endobronchial space, which may be tolerated better by the patient. Under fluoroscopy, an interventional radiologist inserted a catheter over guidewire via tracheostomy. Radiocontrast study with fluoroscopy identified left bronchial tree segment leading to the fistula tract. An occlusive microvascular plug (Reverse Medical Corporation, Irvin, CA, USA) was inserted via this catheter to close the leak. Postprocedure radiocontrast study and high-resolution chest CT showed significant reduction of left upper pneumothorax (50-60\%) with improved left lower lobe atelectasis (Fig. 2). The left intercostal chest tube was clamped, and the patient was observed for recurrence of pneumothorax. Since there was no recurrence of air leak, the chest tube was removed. Eventually, the patient was discharged to a long-term ventilator facility for liberation from the mechanical ventilator. Long-term follow-up after 3 months of discharge revealed successful liberation from the ventilator. The patient only required oxygen set at $2 \mathrm{~L} / \mathrm{min}$. 


\section{Discussion/Conclusion}

$\mathrm{BPF}$ is a rare complication, most commonly developed postoperatively after pneumonectomy [6]. BPF is usually managed with oxygen therapy, chest tube insertion and medical treatment of the condition causing fistula formation. Persistent BPF may require definitive management with surgical repair or occlusive intrabronchial device to close the air leak. Katoch et al. [5] utilized interventional bronchoscopy and sealants and endobronchial devices to close the BPF in 25 patients. They found that nonoperative bronchoscopic interventions to seal the air leaks are effective only in smaller air leaks, i.e. alveolopleural fistula. Results with larger air leaks like leaking stumps are not very encouraging with sealants and endobronchial devices. Sealants and fibrin glue have also been used with intrapleural application to seal intractable pneumothorax in 40 patients by Kinoshita et al. [7]. A limited pulmonary status may not allow endoscopic intervention as the bronchoscope occupies a significant portion of the bronchial lumen, which may not be tolerated by the patient. An advantage of the IR approach is that real-time imaging before procedure, during procedure, and after procedure allows greater precision, control of condition, and confidence in the provided treatment. The operator can reexamine the fistula site by repeat instillation of contrast to see if the tract is completely sealed. In our patient, the interventional radiologist inserted a thin catheter (occupying only about $25 \%$ of the lumen area of bronchi) through tracheostomy, which was well tolerated. The operator successfully performed contrast study and identified the leaking tract and then applied a microvascular plug and sealed the leak. Repeat contrast fluoroscopy right after insertion confirmed the sealed tract without leak. The procedure was well tolerated without any complications.
BPF management is a challenge which requires a multidisciplinary approach and careful assessment to choose the best approach for treatment, especially in high-risk patients with a compromised pulmonary status. For patients who are not suitable candidates for surgical or endoscopic repair, radiologically guided application of an occluding device or sealants are attractive options.

\section{Statement of Ethics}

The authors have no ethical conflicts to disclose. Written informed consent was obtained from the family. There are no patient's identifiers in the case report which may link patient to the report.

\section{Disclosure Statement}

All authors and their relatives have nothing to disclose. No conflict of interest, no financial interest in the subject matter.

\section{Funding Sources}

None.

\section{Author Contributions}

Dr. R.N.: conceived the idea, wrote the case report, extracted data, analyzed data, and wrote and approved the manuscript. Dr. R.H.A.: conceived the idea, extracted data, and wrote and approved the manuscript. Dr. A.N.Z.: extracted data and wrote and approved the manuscript. Dr. A.S.: performed the procedure described, discussed and analyzed data, and wrote and approved the manuscript. Dr. A.M.E.: conceived the idea, extracted data, analyzed data, and wrote and approved the manuscript.

\section{References}

Intrabronchiolar Microvascular Plug Insertion for BPF Repair
1 Nagahiro I, Aoe M, Sano Y, Date H, Andou A, Shimizu N. Bronchopleural fistula after lobectomy for lung cancer. Asian Cardiovasc Thorac Ann. 2007 Jan;15(1):45-8.

2 Malave G, Foster ED, Wilson JA, Munro DD. Bronchopleural fistula - present-day study of an old problem. A review of 52 cases. Ann Thorac Surg. 1971 Jan;11(1):1-10.

3 Shah N, Marwah R, Talwar I. Diagnosis of bronchopleural fistula with thin section CT scans. Bombay Hosp J. 2010;52:254-6.

4 Puskas JD, Mathisen DJ, Grillo HC, Wain JC, Wright CD, Moncure AC. Treatment strategies for bronchopleural fistula. J Thorac Cardiovasc Surg. 1995 May;109(5):989-95.
5 Katoch CD, Chandran VM, Bhattacharyya D, Barthwal MS. Closure of bronchopleural fistula by interventional bronchoscopy using sealants and endobronchial devices. Med J Armed Forces India. 2013 Oct;69(4):326-9.

6 Wright CD, Wain JC, Mathisen DJ, Grillo HC. Postpneumonectomy bronchopleural fistula after sutured bronchial closure: incidence, risk factors, and management. J Thorac Cardiovasc Surg. 1996 Nov;112(5):136771.

7 Kinoshita T, Miyoshi S, Katoh M, Yoshimasu T, Juri M, Maebeya S, et al. Intrapleural administration of a large amount of diluted fibrin glue for intractable pneumothorax. Chest. 2000 Mar;117(3):790-5. 